\title{
Skin Temperature and Body Surface Section in Non-Uniform and Asymmetric Outdoor Thermal Environment
}

\author{
Yoshihito Kurazumi ${ }^{*}$, Kenta Fukagawa ${ }^{2}$, Tomonori Sakoi ${ }^{3}$, \\ Ariya Aruninta ${ }^{4}$, Emi Kondo $^{5}$, Ken Yamashita ${ }^{1}$ \\ ${ }^{1}$ School of Life Studies, Sugiyama Jogakuen University, Nagoya, Japan \\ ${ }^{2}$ Department of Architecture, Kyushu Sangyo University, Fukuoka, Japan \\ ${ }^{3}$ Academic Assembly, Institute of Textile Science and Technology, Shinshu University, Nagano, Japan \\ ${ }^{4}$ Department of Landscape Architecture, Chulalongkorn University, Bangkok, Thailand \\ ${ }^{5}$ Department of Architecture, Ariake National College of Technology, Omuta, Japan \\ Email: *kurazumi@sugiyama-u.ac.jp
}

How to cite this paper: Kurazumi, Y., Fukagawa, K., Sakoi, T., Aruninta, A., Kondo, E. and Yamashita, K. (2018) Skin Temperature and Body Surface Section in Non-Uniform and Asymmetric Outdoor Thermal Environment. Health, 10, 1321-1341. https://doi.org/10.4236/health.2018.1010102

Received: September 3, 2018

Accepted: October 16, 2018

Published: October 22, 2018

Copyright $\odot 2018$ by authors and Scientific Research Publishing Inc. This work is licensed under the Creative Commons Attribution-NonCommercial International License (CC BY-NC 4.0). http://creativecommons.org/licenses/by-nc/4.0/

\begin{abstract}
In indoor environments and shady outdoor environments, there is little influence of short-wavelength solar radiation, so a strikingly non-uniform and asymmetric environment is not formed. In outdoor sunny environment, however, shaded areas occur even for the same site of the body, and a remarkable difference in skin temperature is considered to occur under the influence of the short-wavelength solar radiation. The purpose of this study is to clarify the influence of the non-uniform and asymmetric thermal radiation of short-wavelength solar radiation in outdoor environment on the division of the body surface section and the calculation of the mean skin temperature. The skin temperature of the front of the coronal surface, which was facing the sun and where the body received direct short-wavelength solar radiation, and the skin temperature of the rear of the coronal surface, which was in the shadow and did not receive direct short-wavelength solar radiation were respectively measured. The feet, upper arm, forearm, hand and lower leg, which are susceptible to short-wavelength solar radiation in a standing posture, had a noticeable difference in skin temperature between sites in the sun and in shade. The mean skin temperature of sites facing the sun was significantly higher than the mean skin temperature of those in the shade.
\end{abstract}

\section{Keywords}

Asymmetry, Mean Skin Temperature, Non-Uniform, Outdoor Environment, Physiological Response, Skin Temperature, Solar Radiation 


\section{Introduction}

An extremely large number of laboratory experiments on subjects assume the thermal environment to be in a homogeneous and uniform steady state. However, the ordinary indoor environment is thermally non-uniform, asymmetrical and nonstationary. In addition, the physical thermal environmental factors fluctuate greatly in the outdoor environment, which is in an unsteady state.

Humphreys [1], Brager and de Dear [2], Nikolopoulou et al. [3], de Dear and Brager [4], Nikolopoulou and Steemers [5], Knez and Thorsson [6], Nikolopoulou and Lykoudis [7], and Kántor and Unger [8] mentioned that in outdoor spaces, not only physical and physiological environmental impacts but also psychological environmental impacts affect thermal comfort. In addition, it is also mentioned that based on the thermal environment history, such as cultural background and the experience of hot and cold environments, the expectation of the thermal environment, active body heat control, and exposure time affect the adaptation to the thermal environment.

Givoni et al. [9], Oliveira and Andrade [10], Eliasson et al. [11], Nikolopoulou and Steemers [5], Nikolopoulou and Lykoudis [7], and Ishii et al. [12] studied the relationship between physical environmental factors and human thermal sensation. These studies clarified that the temperature, wind direction, and solar radiation affect the thermal sensation of humans.

Höppe [13], Nikolopoulou and Steemers [5], Spagnolo and de Dear [14], Nakano and Tanabe [15], Ahmed [16], Oliveira and Andrade [10], Lin and Matzarakis [17], Cheng et al. [18], and Hwang et al. [19] mentioned that in outdoor spaces, thermal adaptation results in a thermal sensation different from the indoor environment. In winter, people prefer a lower temperature than in summer, and tolerate higher temperatures in summer than in winter. As in surveys of indoor environments, it is inferred that effects of clothing and environmental history appear as seasonal differences. In addition, in these studies, thermal comfort was targeted at a nonspecific overall comfort feeling rather than a thermally unique pleasant sensation.

However, in these studies, the physiological responses of the human body, which is indispensable for the heat balance of the human body have not been measured. In evaluating the outdoor environment, the psychological reaction of the human body is made the focus, and research quantitatively dealing with the heat balance of the human body is rare. The only studies that quantitatively investigate the influence on the human body using comprehensive thermal environment evaluation indices based on the heat balance of the outdoor environment as the axis of evaluation are those by Kurazumi et al. [20]-[27].

The outdoor thermal environment, short-wavelength solar radiation, long-wavelength thermal radiation and the air current are non-uniform and asymmetric evaluation factors. These may contribute as a local effect on the human body, even if the heat balance in the whole human body is the same. As pointed out by Kurazumi et al. [24] [26] [27], the influence of these environ- 
mental parameters may cause variation in the response of the human body. The human body may experience discomfort due to changing environmental factors, and so this experience can be thought to induce the condition of relative comfort. Accordingly, changes with an effect that mitigates thermal function are considered to be variables for discomfort with regard to other environmental factors also. That is, the degree of conscious awareness of thermal environmental factors may have an influence.

Horikoshi et al. [28] and Kurazumi et al. [29], who conducted heterogeneous and asymmetric subject experiments in an indoor environment, demonstrate that the psychological reactions of the human body in a heterogeneous and asymmetric thermal radiation environment have directionality under the effect of local thermal radiation, and that these psychological reactions change. Kurazumi et al. [30] demonstrate that a parameter exists for the heterogeneous and asymmetric thermal environmental factors in the thermal environment evaluation index that evaluates the effect on the human body in a heterogeneous and asymmetric thermal radiation environment. They show that there is a large spread in the response of the human body due to the effect of this parameter. That is, the spread in thermal sensory perception becomes large in outdoor spaces due to the influence of environmental stimuli in addition to the psychological response to thermal action in the outdoor space.

The thermal environment evaluation index based on the heat balance of the human body in the outdoor environment uses representative values of individual thermal environment factors as evaluation values. The variable factors, Instantaneous variation due to wind and the like or variable factors due to disturbances in measurement values, use the moving average, and the physical non-uniform and asymmetric thermal radiation factor of the environment side use the combined average of the mean radiant temperature. However, the mean skin temperature of the body has an aspect of a representative value of the local environment, however there are few studies that include the effects of short-wavelength solar radiation on the mean skin temperature of the body.

The mean skin temperature, which is the representative value for skin temperature, is used to calculate the amount of heat exchange between the human body and the environment. Since skin temperature is not uniform over the whole body surface, it is assumed that it is uniform within a given site of the body surface and the mean skin temperature is considered to be the skin temperatures averaged by the area of the surfaces as a proportion of the total surface area of the body. That is, the mean skin temperature calculation formula has been devised assuming that the skin temperature is almost uniform on the body surface.

Studies on the method for calculating the mean skin temperature deal with the physiological mean skin temperature and thermal conduction mean skin temperature. There are various measurement points and measurement sites for skin temperature, and considering the relationship between the human body and the 
surrounding environment, it is necessary to determine the sites judged to be affected by the surrounding environment and the distribution of skin temperature. The more skin temperature measurement scores corresponding to the skin temperature distribution are used, the smaller the skin temperature distribution within the body surface section becomes. Therefore, each representative skin temperature approximates the most probable value as the representative section value, and the accuracy of the mean skin temperature calculation is improved. However, it is difficult and impractical to actually measure a large number of measurement points. So far, six types of mean skin temperature calculation method have been proposed as follows.

Studies proposing the mean skin temperature calculation method due to the weight of the body part delineation of the whole body surface area [31]-[48], separates fixed regions that distribute the generated skin temperature on the body surface, then the ratio of the separated body surface area to the total surface area gives the weighted average of the separated representative skin temperature.

Studies that propose a mean skin temperature calculation method based on the convective heat transfer area weighting of the body surface section of the human body [49] [50] divide the distribution of the skin temperature expressed on the body surface by a certain range, and make a weighted average of the section representative skin temperatures by the ratio of the heat section transfer area to the total convective heat transfer area.

Studies that propose a mean skin temperature calculation method based on the total surface area weighting of the human body surface section and the conductive heat transfer area weighting between the body and the floor etc. [51]-[57] divide the distribution of the skin temperature expressed on the body surface by a certain range, and make a weighted average of the section representative skin temperatures by the ratio of the section body surface area to the total body surface area.

Further research by Kurazumi et al. [58] developed the above concept of a weighting coefficient for the heat transfer area. A mean skin temperature calculation method is proposed by a weighting of the convective heat transfer area, the radiative heat transfer area, and the conductive heat transfer area of the human body surface section.

In studies proposing a mean skin temperature calculation method based on the total surface area weighting of the human body surface section and the local convective heat transfer coefficient for the section [59] [60] [61] [62] [63], this was obtained from an equation for the body heat balance between the human body and the surrounding environment.

One study [64] that proposes a mean skin temperature calculation method based on the total surface area weighting and the skin temperature sensation of the surface section of the human body, suggests that temperature sensation is related to the expression of skin temperature. In this study, a perspiration ratio is used for temperature sensation. 
A study proposing a mean skin temperature calculation method based on the total surface area weighting of the body surface section and the local convective heat transfer coefficient and the skin temperature sensation for that section of the human body [65] combined the local convective heat transfer coefficient for the human body obtained from an equation for body heat balance with the weighting coefficient of Nadel et al. [64].

The mean skin temperature calculation formula must be selected according to the application, such as whether the calculated mean skin temperature is used as a monitor of physiological response or applied to the body heat balance equation for the human body. In indoor environments and shady outdoor environments, there is little influence of short-wavelength solar radiation, so a strikingly non-uniform and asymmetric environment is not formed. In an outdoor environment, however, some parts of the body have shaded sites and sites facing the sun, and a remarkable difference in skin temperature is considered to occur under the influence of the short-wavelength solar radiation.

However, there are few studies that investigate the effect of the non-uniform and asymmetric outdoor thermal environment on the division of the body surface section and the mean skin temperature of the human body. Therefore, the present study aimed to clarify the influence of the non-uniform and asymmetric thermal radiation of short-wavelength solar radiation in an outdoor environment on the calculation of the mean skin temperature of the human body and on the classification of the body surface section.

\section{Experiment Design}

\subsection{Experimental Process and Measurement Items}

Experiments were conducted in Bangkok, Thailand at $13^{\circ} 44^{\prime} 20^{\prime \prime}$ north latitude during the dry season. For the measurements, the experiment site was selected with consideration for the condition that short-wavelength solar radiation should not be shielded during the exposure time. Weather environment elements in outdoor spaces are in a heterogeneous and unsteady state. Focusing on the influence of short-wavelength solar radiation, the experiment site chosen for the present study was a place where fluctuations of other weather environmental factors were minimized. A measurement location within the building canyon surrounded by buildings was selected such that the subjects were in an enclosed space and the fluctuation of airflow was mitigated. The sky factor of the measurement location in the building canyon was 0.26 . The building and the ground surface were a concrete material with high heat capacity, so the influence of long-wavelength thermal radiation was strong, but the exposure time frame of 13:00-14:30, where the solar altitude is high and fluctuation of the surface temperature decreases, was selected. During this exposure time, participation experiments were conducted several times.

The thermal environment of outdoor spaces can be harsh to the extent that there are cases of death by heat stroke. Accordingly, extended periods in hot 
outdoor spaces under short-wavelength solar radiation must be avoided. Unlike an indoor space, it is difficult to consider spending extended periods in an outdoor thermal environment that can become uncomfortable due to behavioral thermoregulation by means of environmental refuge behavior. Therefore, the actual measurement of the human body response and the thermal environment was carried out in consideration of the time the subject spent maintaining the standing posture. Naturally, it can be conjectured that the human body response will differ the longer the exposure time of the subjects, but the experimental period was determined with consideration for the safety of the subjects.

Subjects remained upright and at rest in an outdoor shady space for about 60 minutes including the time spent attaching sensors, then moved on foot to the selected site. They were then exposed to the thermal environment in a standing posture for 15 minutes, positioned such that the front of the coronal plane directly faced the direction of the solar azimuth in a place where short-wavelength solar radiation was not obstructed.

The thermal environment parameters measured were: air temperature, humidity, air velocity, globe temperature, and short-wavelength solar heat quantity. Temperature, humidity, air velocity and globe temperature were measured by a portable PMV meter (Kyoto Electronics Manufacturing: AM-101, air temperature: 0 to $50.0^{\circ} \mathrm{C} \pm 0.5^{\circ} \mathrm{C}$, globe temperature: 0 to $50.0^{\circ} \mathrm{C} \pm 0.5^{\circ} \mathrm{C}$, mean radiant temperature: 0 to $50.0^{\circ} \mathrm{C}$, relative humidity: 0 to $100 \% \mathrm{RH} \pm 3 \% \mathrm{RH}$, air velocity: 0 to $1 \mathrm{~m} / \mathrm{s} \pm 0.1 \mathrm{~m} / \mathrm{s} ; 1$ to $5 \mathrm{~m} / \mathrm{s} \pm 0.5 \mathrm{~m} / \mathrm{s}$ ) at a height of $90 \mathrm{~cm}$ above the ground. Concerning the short-wavelength radiant heat quantity from the visible region to the near-infrared region, amounts of downward and upward solar radiation were measured by a pyranometer (PREDE: PCM-01NL, sensitivity: $7 \mathrm{mV} / \mathrm{W} / \mathrm{m}^{-2}$, wavelength range: $305 \mathrm{~nm}$ to $2800 \mathrm{~nm}$ ).

The skin temperature of the human body was measured by a thermistor thermometer (Nikkiso THERM N542R data logger, measuring range: $-50^{\circ} \mathrm{C}$ to $230^{\circ} \mathrm{C}$, resolution: $0.01^{\circ} \mathrm{C}$, and a Nikkiso THERM body surface temperature probe: ITP8391). Surgical tape (NICHIBAN: NICHIBAN SURGICAL TAPE-21N) with superior moisture permeability was used to attach a surface temperature sensor for measuring skin temperature to the human body. The temperature of skin open to airflow was measured at the eight positions of the head, upper arm, forearm, hand, trunk, thigh, lower leg, and foot. The skin temperature of the front of the coronal surface, which was facing the sun and where the body receives short-wavelength solar radiation, and the skin temperature of the rear of the coronal surface, which was in the shadow and did not receive short-wavelength solar radiation, were measured. The subjects were wearing $\mathrm{T}$-shirts and shorts, such that the skin temperature measurement sites were exposed to the surrounding environment. The T-shirts were turned up to expose the upper arm, abdomen and lumbar area. In order to prevent burns due to heat conduction from the ground surface, posture was maintained on sandals with a sole thickness of about $1.0 \mathrm{~cm}$. 


\subsection{Subjects}

The subjects were four healthy young males and females. The subjects were age $21.0 \pm 0.7$ years, height $167.7 \pm 5.8 \mathrm{~cm}$, body weight $56.7 \pm 7.5 \mathrm{~kg}$, body surface area $1.6 \pm 0.1 \mathrm{~m}^{2}$, and BMI $20.1 \pm 2.6$, and they were not considered to have a unique physique. In addition, the subject's height and weight are not significantly different from the average of Thai statistical data [66]. In calculation of the body surface area of the human body, we used a calculation formula of Kurazumi et al. [48]. Table 1 shows the subjects' characteristics.

In accordance with the Helsinki Declaration [67], the details of the experiment were explained to the subjects in advance and their consent for participation in the experiment was obtained.

Experiments with subjects measuring physiological quantities as human body reactions are rarely performed using a large number of subjects. In addition, it is difficult to perform experiments assuming a statistical population. Therefore, although there are few subjects in this study, they are considered meaningful as new data.

It is rare to perform a subjective experiment that measures physiological quantities according to the response of the human body using a large number of subjects. It is difficult to perform an experiment that is hypothesized on a statistical population. Accordingly, as only a small number of subjects was used in this study, the new data are a significant addition to the literature.

\section{Results}

The solar altitude on the experimental days was $72.98^{\circ}-55.81^{\circ}$ and the solar azimuth was $211.01^{\circ}-247.07^{\circ}$. The weather during the exposure time was sunny with the sun occasionally obscured by clouds. The experiment was set up with the time of exposure to short-wavelength direct solar radiation set to 15 minutes, but weather conditions occurred in which the short-wavelength solar radiation was completely shielded. Therefore, in the following discussion, the elapsed exposure time in which all meteorological observation times were satisfied was analyzed as 13 minutes.

The temperature during the experiment was $34.2^{\circ} \mathrm{C} \pm 0.4^{\circ} \mathrm{C}$, relative humidity was $48.7 \% \pm 0.9 \%$, air velocity was $1.9 \pm 0.8 \mathrm{~m} / \mathrm{s}$, globe temperature was $42.5 \pm$

Table 1. Physical characteristics of subjects.

\begin{tabular}{cccccccc}
\hline Subject & Sex & Age & Height $[\mathrm{cm}]$ & Weight $[\mathrm{kg}]$ & B-area $\left[\mathrm{m}^{2}\right]$ & BMI [N.D.] & Native place \\
\hline 1 & Male & 21 & 165.3 & 65.0 & 1.71 & 23.79 & Bangkok \\
2 & Male & 22 & 177.6 & 60.0 & 1.74 & 19.02 & Bangkok \\
3 & Female & 20 & 163.0 & 44.7 & 1.47 & 16.82 & Bangkok \\
4 & Female & 21 & 165.0 & 57.0 & 1.62 & 20.94 & Bangkok \\
\hline
\end{tabular}

B-area is the calculated body surface area by Kurazumi's formula [48]. $\mathrm{S}=100.315 \mathrm{~W}^{0.383} \mathrm{H}^{0.693} \times 10^{-4}(\mathrm{Ku}-$ razumi et al., 1994). S: Body surface area $\left[\mathrm{m}^{2}\right]$, W: Weight $[\mathrm{kg}]$, H: Height $[\mathrm{cm}]$. BMI is Body Mass Index. Native place is life region from birth to 2.5 years old time. 
$1.4^{\circ} \mathrm{C}$, horizontal short-wavelength solar radiation was $766.5 \pm 272.7 \mathrm{~W} / \mathrm{m}^{2}$, ground surface reflected solar radiation quantity was $86.1 \pm 36.1 \mathrm{~W} / \mathrm{m}^{2}$. The observation area albedo was $10.7 \%$. There was also an exposure time zone in which the temperature around the body was higher than the skin temperature.

In a normal posture, the body surfaces are in contact with each other at the armpit and inner surface of the thigh. In the standing posture, it is possible to proactively assume an open posture with respect to the air current. Also, even in a chair seated position, it is possible to be proactively open to the air current to some extent by minimizing the contact area between the human body and the chair. However, there is still some of the body surface that is not open to the air flow, such as contact between the foot and the floor surface (hereinafter "non-convective heat transfer surface"). Non-convective heat transfer surfaces exist in many ordinary postures.

A weighted average method based on the ratio of the total surface area of the body is used in the conventional mean skin temperature calculation method. However, considering the above facts, the calculation of the heat exchange quantity of the body is inaccurate in this conventional method, since non-convective heat transfer surfaces are included. In terms of heat transfer, the mean skin temperature used for accurate calculation of the quantity of convective heat exchange between the body and the environment should be the weighted average given by the area ratio of the convective heat transfer surface formed by the same skin temperature expressed on the body surface open to the air flow (hereinafter "convective heat transfer surface") with respect to the total convective heat transfer surface (hereinafter "convective heat transfer area ratio"). That is, it is necessary to use a mean skin temperature calculation method that considers the convective heat transfer area. Focusing on this point, Kurazumi et al. [49] [58] propose a mean skin temperature calculation method based on the convective heat transfer area weighting of the body surface section.

The present study assumed the perspective of applying the mean skin temperature to the evaluation of the heat balance of the body and evaluation of the thermal environment. Accordingly, to calculate the mean skin temperature, the method based on the convective heat transfer area weighting of the body surface section proposed by Kurazumi et al. [49] [58] was used.

Figure 1 and Figure 2 show examples of skin temperature change over time for the same subject exposed to the outdoor thermal environment for $13 \mathrm{mi}$ nutes. Figure 1 shows an example of skin temperature change of the site facing the sun. A fluctuation of skin temperature considered to be influenced by cooling by perspiration and the influence of changes in air velocity and short-wavelength solar radiation was observed. Since the altitude of the sun was high and the subjects were located such that the front of the coronal plane directly faced the direction of the solar azimuth, the temperature rise is remarkable for the skin of the foot, which is a site susceptible to solar radiation in the direction normal to the short-wavelength solar radiation. The peak skin temperature 


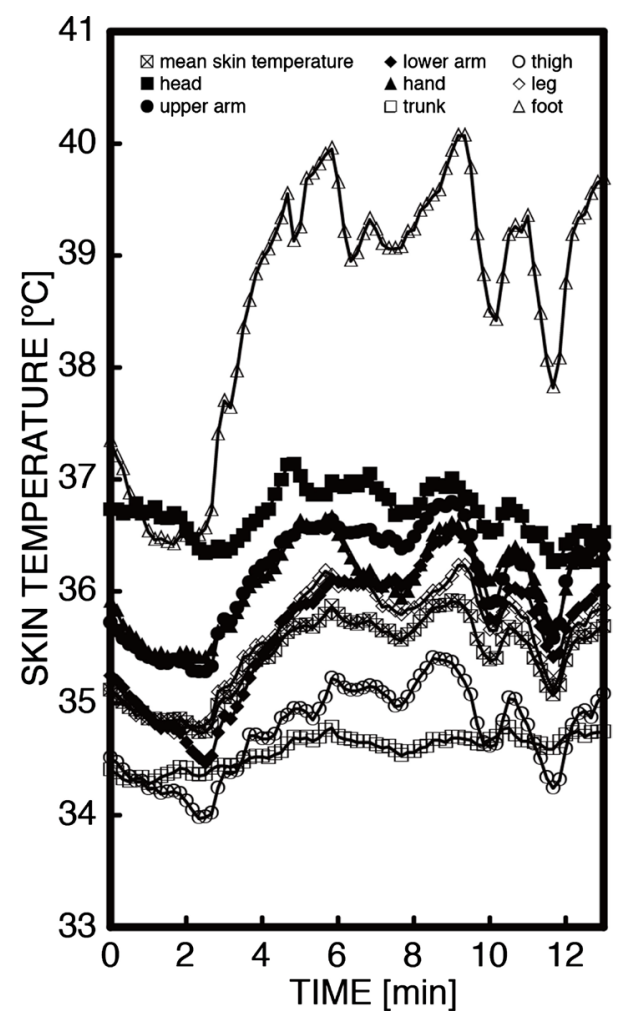

Figure 1. Changes of skin temperature exposed to the outdoor thermal environment in the sunny body part.

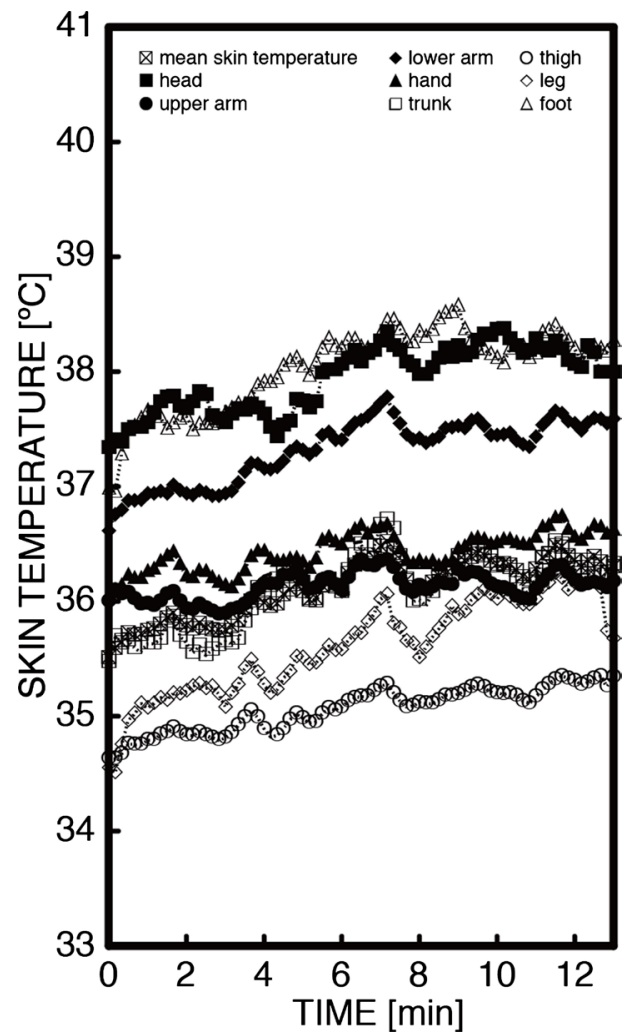

Figure 2. Changes of skin temperature exposed to the outdoor thermal environment in the shady body part. 
was remarkably high at around $40^{\circ} \mathrm{C}$. Next, the skin temperature of the upper arm, forearm, hand and lower leg are also considered to be greatly influenced by short-wavelength solar radiation.

Figure 2 shows an example of skin temperature change of the site in the shade. Although this is for the shaded area of the site shown in Figure 1, a fluctuation of skin temperature considered to be influenced by cooling by perspiration and the influence of changes in air velocity and short-wavelength solar radiation was observed in the same way as above. However, it was not a large fluctuation compared with the skin temperature of sites facing the sun. The skin temperature of the head, upper arm and foot were extremely high, in excess of $37^{\circ} \mathrm{C}$. The amount of change in skin temperature of the same site, for which the skin temperature in the part facing the sun was remarkably high, was increased by about $0.4^{\circ} \mathrm{C}$.

Kurazumi et al. [20] [23] [24] [25] [26] [27] clarified the influence of reflected solar radiation on the human foot, and found that both reflected solar radiation and heat conduction from the ground surface influence the reaction of the human body. However, since the amount of change in the skin temperature of the foot in the sun and in the shade was significantly different, it is inferred that the difference in the skin temperature change is strongly influenced by short-wavelength solar radiation.

\section{Discussion}

Figure 3 shows the change in mean skin temperature over time for skin exposed to the outdoor thermal environment for 13 minutes. Although there is a slight variation by subject, as described above, there was seen to be a fluctuation in the change in mean skin temperature that may have been influenced by cooling by perspiration, as well as fluctuations of air velocity and short-wavelength solar radiation. However, the overall fluctuation tendency tends to be such that the variation in the mean skin temperature of sites facing the sun is higher than the

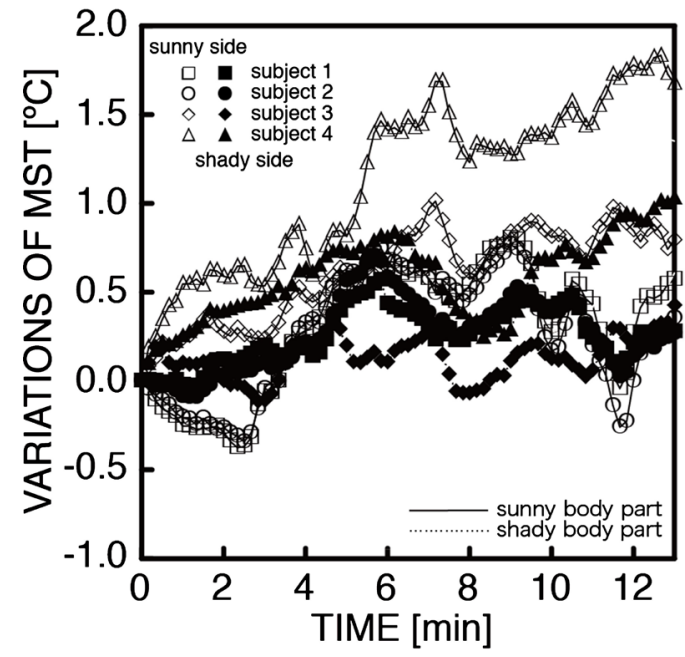

Figure 3. Changes of variation of mean skin temperature. 
variation at sites in the shade, and this variation becomes larger over time. For subjects with the largest difference between the fluctuation of mean skin temperature for sites facing the sun 13 minutes after exposure and the fluctuation at sites in the shade, this was $1.4^{\circ} \mathrm{C}$. Meanwhile, this was $0.3^{\circ} \mathrm{C}$ for the lowest subjects.

There are very few studies that actually measure the skin temperature of the human body in a non-uniform and asymmetric thermal environment. The research of Horikoshi et al. [68] and Kurazumi et al. [29] [30] measured the influence on human skin temperature from the perspective of a non-uniform and asymmetric thermal environment in an indoor space. The research of Maruyama and Tamura [69] measured the influence on human skin temperature from the perspective of sites covered by clothing and open to the atmosphere. These studies demonstrate that variations in skin temperature are exhibited in a non-uniform and asymmetric thermal environment according to the influence of the local conditions.

As a result of investigating the difference between the fluctuation in mean skin temperature in sites facing the sun and the fluctuations in sites in the shade, a significant difference of $\mathrm{p}<0.01(\mathrm{~F}=146.1)$ is shown. Also, as a result of investigating the difference between the fluctuation in mean skin temperature in sites facing the sun and the fluctuations in sites in the shade and their interaction over exposure time, a significant difference of $\mathrm{p}<0.01(\mathrm{~F}=51.1)$ is shown.

In an outdoor environment in which the local influence on the human body becomes stronger, the tendency for the variation in the skin temperature to become stronger may be more pronounced because the thermal radiation environment is more non-uniform and asymmetrical due to short-wavelength solar radiation. This suggests that, when clarifying the effect on the human body in an outdoor environment, it is necessary to take into account the non-uniformity and asymmetry of the skin temperature for sites facing the sun and in the shade. Accordingly, when evaluating the body heat balance of the human body and the thermal environment in an outdoor environment, it is essential to consider the non-uniformity and asymmetry not only of the physical elements of the environment, but also of the skin temperature, which is an element on the side of the human body.

To examine the heat exchange between the human body and the environment, subject experiments are effective. However, depending on human body conditions and environmental conditions, it is sometimes difficult to conduct subject experiments. In such cases, it is effective to use a thermal manikin or a numerical thermal manikin. There are various models that have been developed to characterize the thermoregulation of humans, which measure the physiological factors of humans. There is the relatively simplified Wissler cylinder model [70], Atkins and Wyndham [71] revised the Wissler model, and there is also Gagge et al.'s Two-Node Model [72] [73] [74]. Those which take into account the human shape include Stolwijk and Hardy [75], Stolwijk [76], Smith [77], Takemori et al. 
[78], Fu [79], Yokoyama et al. [80] [81] [82], Tanabe et al. [83], Huizenga et al. [84], McGuffin et al. [85], Kohri and Mochida [86], Ozeki et al. [87], Sakoi et al. [88], Kuwabara et al. [89], Park and Tuller [90] and Kurazumi et al. [91]. These have been developed to allow for the evaluation of asymmetric thermal environments, and non-steady-state environments.

The thermal manikin body is divided into several sections from the head to the lower limb, so there is a possibility that the thermal manikin can estimate the heat exchange between the non-uniform and asymmetric thermal environment and the human body. If we know the heat transfer characteristics and the sensational and physiological temperature of the thermal environment for each divided part, we can evaluate the influence of the thermal environment on the human body in detail.

Representative body surface division of the human body and of the thermal manikin body are head, trunk, upper arm, forearm, hand, thigh, lower leg, and foot. The head and trunk may be further subdivided. Although, it is possible to study the asymmetric difference between the left and right thermal radiation stimuli received from the thermal environment targeted at the limbs, it is difficult to consider other non-uniform and asymmetric thermal environments and other body surface section to be examined. In indoor environments and outdoor environments, there is strong influence of short-wavelength solar radiation, so a strikingly non-uniform and asymmetric environment is formed.

When simulating a long-wavelength thermal radiation environment by means of the numerical thermal manikin, the angle factor between the human body and the environment and radiant heat transfer area factor of the human body (effective radiation area factor) are essential. Although there are measurement values for the whole human body, measurement values of radiant heat transfer area factor (effective radiation area factor) for each part of the body have been carried out by Tsuchikawa et al. [92]. However, since there are differences in a thermal manikin with a human form and numerical thermal manikin, there are differences in how parts are delineated which makes using actual data difficult. Therefore, when simulating the whole human body, analysis using measured values of the human body is possible, yet for simulations of each part use uncertain coefficient values which reduces their validity. Kurazumi et al. [93] identify problems with these human body coefficients.

Also, when simulating short-wavelength solar radiation environments numerical thermal manikin, it is necessary to calculate the direct solar radiation on the body and sky radiation on the body, reflected solar radiation from the body. When doing this, the projected area factor and radiant heat transfer area factor (effective radiation area factor) are essential. Focusing on the projected area factor for the whole human body, Underwood [94], Fanger [95], and Miyamoto [96] have human body measurement values however, the projected area factor for each part of the body have not been measured. Although it is possible to make calculations using a human shaped model [90], since there is little refer- 
ence material on contact points on the body for numerical thermal manikin and human body measurements have not been made, the validity of these cannot be verified. Also, the large effects of long-wavelength thermal radiation in outside environments have been confirmed from measurements made by Kurazumi et al. [25] [26] [27]. Therefore, the previously mentioned radiant heat transfer area factor from each body part (effective radiation area factor) is a problem.

For analyses with a numerical thermal manikin, the body model is a combination of models of body parts. The basic shape for the models of body parts consist of spheres and cylinders. Therefore, the left-right asymmetric thermal radiation environment can be verified within a certain range, yet evaluating the uneven thermal environment factors for the parts is difficult.

As mentioned above and with the identified research as a basis, there is very little foundation for properly evaluating simulations using a numerical thermal manikin for the uneven thermal radiation environment. Furthermore, the validity of skin temperature calculated from the numerical thermal manikin and the skin temperature of a human body have not been verified. Also, in research on the identified series of outdoor environment field studies, skin temperatures corresponding to uneven environments have not been measured. In addition, the basis for applying studies on interior spaces to outdoor spaces has not been shown. There is only Kurazumi et al. [91] that verified the consistency with the simulation value of the measured value of the skin temperature of the human body in outdoor environment. It can be studied to the body heat balance of the whole body and some extent on the left and right asymmetry. However, the model of the human body is a combination of models of parts of the human body, and it is difficult to evaluate the non-uniform elements in the site.

From the results of this study, in order to reference the non-uniform and asymmetry of skin temperature, which is a human body factor for numerical simulations and measurement of mean skin temperature, it is necessary to divide the front and back along the coronal plane of the limbs, and not only for the head and trunk. From this, a more detailed evaluation of the effects on the human body from the thermal environment can be made.

\section{Conclusions}

In an outdoor environment, some parts of the body have shaded sites and sites facing the sun, and a remarkable difference in skin temperature is considered to occur under the influence of short-wavelength solar radiation. When evaluating the body heat balance of the human body and the thermal environment in an outdoor environment, it is essential to consider the non-uniformity and asymmetry not only of the physical elements of the environment, but also of the skin temperature, which is an element on the side of the human body. Therefore, when applying the mean skin temperature to the body heat balance equation of the human body, it is necessary to consider the influence of short-wavelength solar radiation. 
Therefore, the present study aimed to clarify the influence of the non-uniform and asymmetric thermal radiation of short-wavelength solar radiation in an outdoor environment on the calculation of the mean skin temperature of the human body and on the classification of the body surface section.

A fluctuation of skin temperature considered to be influenced by cooling through perspiration and the influence of changes in air velocity and short-wavelength solar radiation was observed. The temperature of skin when receiving short-wavelength solar radiation due to the positional relation close to the normal direction was remarkably high at about $40^{\circ} \mathrm{C}$. The feet, upper arm, forearm, hand and lower leg, which are susceptible to short-wavelength solar radiation in a standing posture, had a noticeable difference in skin temperature between sites in the sun and in shade. The mean skin temperature of sites facing the sun was significantly higher than that of those in the shade. When evaluating the body heat balance of the human body and the thermal environment in an outdoor environment, it is essential to consider the non-uniformity and asymmetry not only of the physical elements of the environment, but also of the skin temperature, which is an element on the side of the human body.

The measurement of mean skin temperature, and the combination of thermal manikin need to be divided not only in the head and trunk but also in the limbs into the anterior part and the posterior part of the coronal plane. We can evaluate the influence of the thermal environment on the human body in detail.

\section{Acknowledgements}

We would like to express our sincerest gratitude to the study subjects who participated in the present study. In conducting this study, we would like to express our sincerest gratitude to the people who cooperated in the experiment and measurements. This work was supported by JSPS KAKENHI Grant Number JP18H01594.

\section{Conflicts of Interest}

The authors declare no conflicts of interest regarding the publication of this paper.

\section{References}

[1] Humphreys, M. (1976) Field Studies of Thermal Comfort Compared and Applied. Building Services Engineer, 44, 5-27.

[2] Brager, G.S. and de Dear, R.J. (1998) Thermal Adaptation in the Build Environment: A literture Review. Energy and Buildings, 27, 83-96.

https://doi.org/10.1016/S0378-7788(97)00053-4

[3] Nikolopoulou, M., Baker, N. and Steemers, K. (2001) Thermal Comfort in Outdoor Urban Spaces, Understanding the Human Parameter. Solar Energy, 70, 227-235. https://doi.org/10.1016/S0038-092X(00)00093-1

[4] de Dear, R.J. and Brager, G.S. (2002) Thermal Comfort in Naturally Ventilated Buildings, Revisions to ASHRAE Standard 55. Energy and Buildings, 34, 549-561. 
https://doi.org/10.1016/S0378-7788(02)00005-1

[5] Nikolopoulou, M. and Steemers, K. (2003) Thermal Comfort and Psychological Adaptation as a Guide for Designing Urban Spaces. Energy and Buildings, 35, 95-101.

[6] Knez, I. and Thorsson, S. (2006) Influence of Culture and Environmental Attitude on Thermal, Emotional and Perceptual Evaluations of a Square. International Journal of Biometeorol, 50, 258-268. https://doi.org/10.1007/s00484-006-0024-0

[7] Nikolopoulou, M. and Lykoudis, S. (2006) Thermal Comfort in Outdoor Urban Spaces: Analysis across Different European Countries. Building and Environment, 41, 1455-1470. https://doi.org/10.1016/j.buildenv.2005.05.031

[8] Kántor, N. and Unger, J. (2011) Benefits and Opportunities of Adopting GIS in Thermal Comfort Studies in Resting Places: An Urban Park as an Example. Landscape and Urban Planning, 98, 36-46.

https://doi.org/10.1016/j.landurbplan.2010.07.008

[9] Givoni, B., Noguchi, M., Saaroni, H., Pochter, O., Yaacov, Y., Feller, N. and Becker, S. (2003) Outdoor Comfort Research Issues. Energy and Buildings, 35, 77-86. https://doi.org/10.1016/S0378-7788(02)00082-8

[10] Oliveira, S. and Andrade, H. (2007) An Initial Assessment of the Bioclimatic Comfort in an Outdoor Public Space in Lisbon. International Journal of Biometeorology, 52, 69-84. https://doi.org/10.1007/s00484-007-0100-0

[11] Eliasson, I., Knez, I., Westerberg, U., Thorsson, S. and Lindberg, F. (2007) Climate and Behaviour in a Nordic City. Landscape and Urban Planning, 82, 72-84. https://doi.org/10.1016/j.landurbplan.2007.01.020

[12] Ishii, J., Horikoshi, T., Kurazumi, Y., Nagano, K. and Fukagawa, K. (2008) A Field Survey of Thermal Comfort in Outdoor Space. ICB2008 18 th International Congress of Biometeorology, Tokyo, 22-26 September 2008, 1-4.

[13] Höppe, P. (2002) Different Aspects of Assessing Indoor and Out-Door Thermal Comfort. Energy and Buildings, 34, 661-665.

[14] Spagnolo, J. and de Dear, R.J. (2003) A Field Study of Thermal Comfort in Outdoor and Semi-Outdoor Environments in Subtropical Sydney Australia. Building and Environment, 38, 721-738. https://doi.org/10.1016/S0360-1323(02)00209-3

[15] Nakano, J. and Tanabe, S. (2004) Thermal Comfort and Adaptation in Semi-Outdoor Environments. ASHRAE Transactions, 110, 543-553.

[16] Ahmed, K.S. (2003) Comfort in Urban Spaces: Defining the Boundaries of Outdoor Thermal Comfort for the Tropical Urban Environments. Energy and Buildings, 35, 103-110. https://doi.org/10.1016/S0378-7788(02)00085-3

[17] Lin, T.P. and Matzarakis, A. (2008) Tourism Climate and Thermal Comfort in Sun Moon Lake, Taiwan. International Journal of Biometeorology, 52, 281-290. https://doi.org/10.1007/s00484-007-0122-7

[18] Cheng, M., Lo, J. and Chen, S. (2011) Investigation of the Effect of Climatic Adaptation on Users' Thermal Comfort Requirement in Outdoor Space. International Journal of the Physical Sciences, 6, 6042-6052.

[19] Hwang, R.L. and Lin, T.P. (2011) Thermal Comfort Requirements for Occupants of Semi-Outdoor and Outdoor Environments in Hot-Humid Regions. Architectural Science Review, 50, 357-364. https://doi.org/10.3763/asre.2007.5043

[20] Kurazumi, Y., Tsuchikawa, T., Matsubara, N., Kondo, E. and Horikoshi, T. (2011) Evaluation of Enhanced Conduction-Corrected Modified Effective Temperature ETFe as the Outdoor Thermal Environment Evaluation Index. Energy and Build- 
ings, 43, 2925-2937. https://doi.org/10.1016/j.enbuild.2011.07.019

[21] Kurazumi, Y., Matsubara, N., Tsuchikawa, T., Kondo, E., Ishii, J., Fukagawa, K., Ando, Y., Yamato, Y., Tobita, K. and Horikoshi, T. (2011) Psychological Effects of the Environmental Stimuli on Thermal Sense in Outdoor Spaces. Japanese Journal of Biometeorology, 48, 129-144.

[22] Kurazumi, Y., Tsuchikawa, T., Kondo, E., Ishii, J., Fukagawa, K., Yamato, Y., Tobita, K., Ando, Y., Matsubara, N. and Horikoshi, T. (2012) Thermal Comfort Zone in Outdoor Environment. Journal of Human and Living Environment, 19, 115-127.

[23] Kurazumi, Y., Kondo, E., Ishii, J., Sakoi, T., Fukagawa, K., Bolashikov, Z.D., Tsuchikawa, T., Matsubara, N. and Horikoshi, T. (2013) Effect of the Environmental Stimuli upon the Human Body in Winter Outdoor Thermal Environment. Journal of Environmental and Public Health, 2013, Article ID: 418742.

[24] Kurazumi, Y., Ishii, J., Kondo, E., Fukagawa, K., Bolashikov, Z.D., Sakoi, T., Tsuchikawa, T., Matsubara, N. and Horikoshi, T. (2014) The Influence of Outdoor Thermal Environment on Young Japanese Female. International Journal of Biometeorology, 58, 963-974. https://doi.org/10.1007/s00484-013-0681-8

[25] Kurazumi, Y., Ishii, J., Fukagawa, K. and Aruninta, A. (2015) The Influence of Tropical Urban Climate upon the Human Body. International Joint Conference of SENVAR-iNTA-AVAN, Johor, 24-26 November 2015, 105-114.

[26] Kurazumi, Y., Ishii, J., Fukagawa, K., Kondo, E. and Aruninta, A. (2016) Ethnic Differences in Thermal Responses between Thai and Japanese Females in Tropical Urban Climate. American Journal of Climate Change, 5, 52-68. https://doi.org/10.4236/ajcc.2016.51007

[27] Kurazumi, Y., Ishii, J., Fukagawa, K., Kondo, E., Nyilas, A. and Aruninta, A. (2017) Seasonal Differences of Psychological and Physiological Responses in Tropical Urban Climate. Health, 9, 896-920. https://doi.org/10.4236/health.2017.96064

[28] Horikoshi, T., Kurazumi, Y., Hirayama, K., Tsuchikawa, T. and Kobayashi, Y. (1989) Indication of the Effect of Asymmetric Thermal Radiation of the Human Physiological and Psychological Responses. 2nd World Congress on Heating, Ventilating, Refrigerating and Air-Conditioning III, Sarajevo, 27 August-1 September 1989, 188-193.

[29] Kurazumi, Y., Horikoshi, T., Hirayama, K., Tsuchikawa, T. and Kobayashi, Y. (1993) The Influence of Asymmetric and Uneven Thermal Radiation Environments upon the Human Body: In the Case of Constant Operative Temperature. Journal of Architecture, Planning and Environmental Engineering, 447, 17-26.

[30] Kurazumi, Y., Saito, K. and Horikoshi, T. (1994) The Influence of Asymmetric Thermal Radiation Environments upon the Human Body: In the Case of Constant Operative Temperature and Right and Left, Back and Forth Asymmetry. Japanese Journal of Biometeorology, 31, 75-84.

[31] Pfleiderer, H. (1993) Studien über den Würmehaushalt des Menschen. Zeitschrift für die Gesamte Experimentelle Medizin, 90, 245-296. https://doi.org/10.1007/BF02610782

[32] Burton, A.C. (1935) Human Calorimetry II. The Average Temperature of the Tissues of the Body. Journal of Nutrition, 9, 261-280. https://doi.org/10.1093/jn/9.3.261

[33] Winslow, C.-E.A., Herrington, L.P. and Gagge, A.P. (1936) A New Method of Partitional Calorimetry. American Journal of Physiology, 116, 641-655. https://doi.org/10.1152/ajplegacy.1936.116.3.641

[34] Hardy, J.D. and DuBois, E.F. (1938) The Technic of Measuring Radiation and Convection. Journal of Nutrition, 15, 461-475. https://doi.org/10.1093/jn/15.5.461 
[35] Palmes, E.D. and Park, C.R. (1947) Thermal Regulation during Early Acclimatization to Work in a Hot Dry Environment. Bulletin of the United States Army Medical Department Field Research Laboratory, Report 2-17-1, Fort Knox, Kentucky.

[36] Research Committee on Physiological Reaction to Climatic Seasonal Change, 7th Division of Scientific Research Aid Board, Department of Education, Japan (1952) Seasonal Variations of Skin Temperature Distribution of Japanese Male Adults. Nisshin Igaku, 39, 121-136.

[37] Kurata, M. and Funazu, Y. (1954) A Practical Method of Evaluating Mean Skin Temperature. The Journal of Science of Labour, 30, 332-337.

[38] Teichner, W.H. (1958) Assessment of Mean Body Surface Temperature. Journal of Applied Physiology, 12, 169-176. https://doi.org/10.1152/jappl.1958.12.2.169

[39] Iampietro, P.F., Bass, D.E. and Buskirk, E.R. (1958) Heat Exchanges of Nude Men in the Cold: Effect of Humidity, Temperature and Wind Speed. Journal of Applied Physiology, 12, 351-356. https://doi.org/10.1152/jappl.1958.12.3.351

[40] Miura, T., Morioka, M., Kimura, K., Akutsu, A., Hyodo, S., Osawa, H., Tihira, Y. and Okazima, T. (1960) Experimental Studies on the Optimum Temperature of Room Cooling in Summer in Relation to the Outdoor Temperature. The Journal of Science of Labour, 36, 283-336.

[41] Miura, T., Kimura, K., Akutsu, A., Sato, T., Morioka, M., Kogi, K., Takagi, K., Masuda, T. and Nishibe, T. (1962) Experimental Studies on the Optimum Temperature of Room Cooling for Lightly Clothed Men in Summer in Relation to the Outdoor Temperature (Part I). The Journal of Science of Labour, 38, 198-214.

[42] Ramanthan, N.L. (1964) A New Weighting System for Mean Surface Temperature of the Human Body. Journal of Applied Physiology, 19, 531-533. https://doi.org/10.1152/jappl.1964.19.3.531

[43] Stolwijk, J.A.J. and Hardy, J.D. (1966) Partitional Calorimetric Studies of Responses of Man to Thermal Transients. Journal of Applied Physiology, 21, 967-977. https://doi.org/10.1152/jappl.1966.21.3.967

[44] Mitchell, D. and Wyndham, C.H. (1969) Comparison of Weighting Formulas for Calculating Mean Skin Temperature. Journal of Applied Physiology, 26, 616-622. https://doi.org/10.1152/jappl.1969.26.5.616

[45] Sasaki, T., Yasumito, I., Mizukami, M., Inoue, T., Ishihara, A. and Taniguchi, M. (1969) Observation of the Seasonal Change in Metabolism of Japanese in the Basic Condition. The Bulletin of the Constitutional Medical Research Institute, Kumamoto University, 20, 72-78. (In Japanese)

[46] Nadel, E.R., Bullars, R.W. and Stolwijk, J.A.J. (1971) Importance of Skin Temperature in the Regulation of Sweating. Journal of Applied Physiology, 31, 80-87. https://doi.org/10.1152/jappl.1971.31.1.80

[47] Roberts, M.F., Wenger, C.B., Stolwijk, J.A.J. and Nadel, E.R. (1977) Skin Blood Flow and Sweating Changes Following Exercise Training and Heat Acclimation. Journal of Applied Physiology, 43, 133-137. https://doi.org/10.1152/jappl.1977.43.1.133

[48] Kurazumi, Y., Horikoshi, T., Tsuchikawa, T. and Matsubara, N. (1994) The Body Surface Area of Japanese. Japanese Journal of Biometeorology, 31, 5-29.

[49] Kurazumi, Y., Tuchikawa, T., Torii, T., Kakutani, K., Matsubara, N. and Horikoshi, T. (2004) Weighting Coefficients for Calculating Mean Skin Temperature When Considering Convective Heat Transfer Areas. Journal of the Human-Environmental System, 7, 19-28. https://doi.org/10.1618/jhes.7.19

[50] Kurazumi, Y., Tsuchikawa, T., Kakutani, K., Yamato, Y., Torii, T., Matsubara, N. 
and Horikoshi, T. (2004) Mean Skin Temperature Taking into Account Convective Heat Transfer Areas-Calculation Method of Seiza Sitting, Cross-Legged Sitting, Sideway Sitting, Both-Knees-Erect Sitting, Leg-Out Sitting, Lateral and Supine Positions. Journal of Environmental Engineering, 585, 19-26.

https://doi.org/10.3130/aije.69.19_2

[51] Horikoshi, T., Dohi, M. and Tsuji, C. (1987) Experimental Study on the Influence of Thermal Conditions upon the Human Physiological and Psychological Responses in Air-Conditioned Room. The Annals of Physiological Anthropology, 6, 255-266. https://doi.org/10.2114/ahs1983.6.255

[52] Sakai, K., Choi, Y., Umemura, S., Horikoshi, T. and Mizutani, A. (1992) The Effect of Air and Floor Temperature on the Human Skin Temperature, Thermal Sensation and Heat Balance. Annual Meeting of Architectural Institute of Japan Environmental Engineering, 999-1000.

[53] Miyamoto, S., Taniguchi, Y., Araki, K., Tsuchikawa, T., Choi, Y. and Horikoshi, T. (1994) Index of Thermal Environment in a Floor-Heated Room and Its Verification. Annual Meeting of Architectural Institute of Japan Environmental Engineering, 351-352.

[54] Choi, Y., Horikoshi, T., Miyamoto, S. and Mizutani, A. (1996) Combined Effect of Air and Heated Floor Temperature on Man in Japanese Sitting Posture. Journal of Architecture, Planning and Environmental Engineering, 480, 7-14.

[55] Watanabe, S., Horikoshi, T., Miyoshi, Y., Miyamoto, S. and Mizutani, A. (1997) Thermal Effect of Heating Facility KOTATSU on the Human Body in Japanese Style Room. Journal of Architecture, Planning and Environmental Engineering, 497, $39-45$.

[56] Kurazumi, Y., Yamato, Y., Yamamoto, S. and Matsubara, N. (1997) The New Weighting Coefficients of Mean Skin Temperature Calculating Formulas in Relation to Posture. Japanese Journal of Biometeorology, 34, 101-112.

[57] Kurazumi, Y., Matsubara, N., Furukawa, N., Fujiwara, M., Ue, A., Ueki, Y., Nagai, H. and Yamamoto, S. (1998) Japanese Weighting Coefficients for Calculating Mean Skin Temperature in Relation to Posture. Japanese Journal of Biometeorology, 35, 121-132.

[58] Kurazumi, Y., Tsuchikawa, T., Ishii, J., Fukagawa, K., Yamato, Y. and Matsubara, N. (2008) Radiative and Convective Heat Transfer Coefficients of the Human Body in Natural Convection. Building and Environment, 43, 2142-2153. https://doi.org/10.1016/j.buildenv.2007.12.012

[59] Mochida, T. and Nishi, Y. (1971) Calculating Mean Skin Temperature in Relation to Local Heat Transfer Coefficient. Annual Meeting of the Society of Heating, Air-Conditioning and Sanitary Engineers of Japan, 95-98. (In Japanese)

[60] Mochida, T. (1972) Calculating Mean Skin Temperature by Means of Engineering Method. 6th Annual Meeting of Hokkaido Branch of the Society of Heating, Air-Conditioning and Sanitary Engineers of Japan, 5-6. (In Japanese)

[61] Mochida, T. (1977) Mean Skin Temperature Weighted with Both Heat Transfer Coefficient and Skin Area. Transactions of AIJ, 259, 67-73.

[62] Ishigaki, H., Horikoshi, T., Mochida, T. and Uematsu, T. (1991) Experimental Determination of Convective Heat Transfer Coefficient for the Human Body Part 5. Annual Meeting of Architectural Institute of Japan Environmental Engineering, 725-726.

[63] Kuwabara, K., Mochida, T., Nagano, K. and Shimakura, K. (2001) Fundamental Study of Weighting Factor for Calculating Mean Skin Temperature. Journal of $\mathrm{Hu}-$ 
man and Living Environment, 8, 33-40.

[64] Nadel, E.R., Mitchell, J.W. and Stolwijk, J.A.J. (1973) Differential Thermal Sensitivity in the Human Skin. Pflügers Archiv, 340, 71-76.

https://doi.org/10.1007/BF00592198

[65] Mochida, T. (1982) Weighting Coefficient for Calculating Mean Skin Temperature. Japanese Journal of Biometeorology, 19, 55. (In Japanese)

[66] Jordan, S., Lim, L., Seubsman, S., Bain, C. and Sleigh, A. (2012) Secular Changes and Predictors of Adult Height for 86105 Male and Female Members of the Thai Cohort Study Born between 1940 and 1990. Journal of Epidemiology and Community Health, 66, 75-80. https://doi.org/10.1136/jech.2010.113043

[67] World Medical Association (2018) WMA Declaration of Helsinki-Ethical Principles for Medical Research Involving Human Subjects.

https://www.wma.net/policies-post/wma-declaration-of-helsinki-ethical-principlesfor-medical-research-involving-human-subjects/

[68] Horikoshi, T., Tsuchikawa, T., Kurazumi, Y., Hirayama, K. and Kobayashi, Y. (1990) Indication of Asymmetric and Uneven Thermal Radiation Environment Related to Thermal Comfort and Discomfort. Journal of Architecture, Planning and Environmental Engineering, 413, 21-28.

[69] Maruyama, Y. and Tamura, T. (1989) Responses of Skin Temperature to Unevenly Distributed and Thermal Sensation Thermal Stimuli. Japanese Journal of Biometeorology, 26, 143-154.

[70] Wissler, E.H. (1961) Steady-State Temperature Distribution in Man. Journal of Applied Physiology, 16, 734-740. https://doi.org/10.1152/jappl.1961.16.4.734

[71] Atkins, A.R. and Wyndham, C.H. (1969) A Study of Temperature Regulation in the Human Body with the Aid of an Analogue Computer. Pflugers Archiv, 307, 104-119. https://doi.org/10.1007/BF00586467

[72] Gagge, A.P., Stolwijk, J.A.J. and Nishi, Y. (1971) An Effective Temperature Scale Based on a Simple Model of Human Physiological Regulatory Response. ASHRAE Transactions, 77, 247-262.

[73] Gagge, A.P., Nishi, Y. and Nevins, R.G. (1977) The Role of Clothing in Meeting FEA Energy Conversation Guidelines. ASHRAE Transactions, 82, 234-247.

[74] Gagge, A.P., Fobelets, A.P. and Bergund, L.G. (1986) A Standard Simulated Index of Human Response to the Thermal Environment. ASHRAE Transactions, 92, 709-731.

[75] Stolwijk, J.A.J. and Hardy, J.D. (1966) Temperature Regulation in Man: A Theoretical Study. Pflugers Archiv, 291, 129-162. https://doi.org/10.1007/BF00412787

[76] Stolwijk, J.A.J. (1971) A Mathematical Model of Physiological Temperature Regulation in Man. NASA-Langley, CR-1855.

[77] Smith, C.E. (1933) A Transient, Three-Dimentional Model of the Human Thermal System. PhD Dissertation, Kansas State University, Manhattan.

[78] Takemori, T., Nakajima, T. and Shoji, Y. (1995) A Fundamental Model of the Human Thermal System for Simulation of Thermal Comfort. Transactions of the Japan Society of Mechanical Engineers, 61, 297-304.

[79] Fu, G. (1995) A Transient, 3-D Mathematical Thermal Model for Clothed Human. Dissertation, Mechanical Engineering, Kansas State University, Manhattan.

[80] Yokoyama, S., Kakuta, N., Togashi, T., Hamada, Y., Nakamura, M. and Ochifuji, K. (2000) Development of Simulation Computer Program of Whole Body Temperatures Expressing Local Characteristic of Each Segment, Part 1 Bio-Heat Equations 
and Solving Method. Transactions of the Society of Heating, Air-Conditioning and Sanitary Engineers of Japan, 77, 1-12.

[81] Yokoyama, S., Kakuta, N., Togashi, T., Hamada, Y., Nakamura, M. and Ochifuji, K. (2001) Development of Simulation Computer Program of Whole Body Temperatures Expressing Local Characteristic of Each Segment, Part 2 Analysis of the Mathematical Model for the Control of Skin Blood Flow. Transactions of the Society of Heating, Air-Conditioning and Sanitary Engineers of Japan, 78, 1-8.

[82] Yokoyama, S., Kakuta, N., Togashi, T., Nakamura, M., Masaki, T., Hamada, Y., Nakamura, M. and Ochifuji, K. (2002) Development of Simulation Computer Program of Whole Body Temperatures Expressing Local Characteristic of Each Segment, Part 3. A Comparison of Experimental and Calculated Results of Body Temperatures. Transactions of the Society of Heating, Air-Conditioning and Sanitary Engineers of Japan, 84, 43-52.

[83] Tanabe, S., Nakano, J. and Kobayashi, S. (2001) Development of 65-Node Thermoregulation-Model for Evaluation of Environment. Journal of Architecture and Planning, 541, 9-16. https://doi.org/10.3130/aija.66.9_2

[84] Huizenga, C., Hui, Z. and Arens, E. (2001) A Model of Human Physiology and Comfort for Assessing Complex Thermal Environments. Buildings and Environment, 36, 691-699. https://doi.org/10.1016/S0360-1323(00)00061-5

[85] McGuffin, R., Burke, R., Huizenga, C., Hui, Z., Vlahinos, A. and Fu, G. (2002) Human: Thermal Comfort Model and Manikin. SAE Technical Papers 2002-01-1955, SAE Future Car Congress, Arlington.

[86] Kohri, I. and Mochida, T. (2003) Simulation Method of Regional Skin Temperature with Dispersed Two-Node Model. Transactions of the Society of Heating, Air-Conditioning and Sanitary Engineers of Japan, 88, 73-82.

[87] Ozeki, Y., Hiramatsu, T. and Tanabe, S. (2004) Comparison of Skin Surface Temperatures between Subjective Experiments and Numerical Simulated by Using a Modified 65MN Thermoregulation Model under Solar Radiation. Journal of Environmental Engineering, 581, 29-36. https://doi.org/10.3130/aije.69.29_3

[88] Sakoi, T., Tsuzuki, K., Kato, S., Ooka, R., Song, D. and Zhu, S. (2007) Study on Evaluation Method for Non-Uniform Thermal Environment, Part 3 Expression of Thermal Comfort in Sitting People in Terms of Local Skin Temperatures and Local Dry Heat Losses. Transactions of the Society of Heating, Air-Conditioning and Sanitary Engineers of Japan, 126, 1-10.

[89] Kuwabara, K., Kubota, H., Hamada, Y., Nakamura, M., Nakaya, N., Amemiya, S. and Nagano, K. (2009) Simulation of Mean Skin Temperature in Hot Outdoor Environment Considering Sweat Efficiency and Wet Clothing. Transactions of the Society of Heating, Air-Conditioning and Sanitary Engineers of Japan, 144, 1-10.

[90] Park, S. and Tuller, S.E. (2011) Comparison of Human Radiation Exchange Models. Theoretical and Applied Climatology, 105, 357-370. https://doi.org/10.1007/s00704-010-0388-2

[91] Kurazumi, Y., Sakoi, T., Tsuchikawa, T., Fukagawa, K., Bolashikov, Z.D. and Horikoshi, T. (2014) Behavioral Thermoregulation Model for Evaluation of Outdoor Thermal Environment. Journal of Ergonomics, 4, 1-14. https://doi.org/10.4172/2165-7556.1000125

[92] Tsuchikawa, T., Horikoshi, T., Kondo, E., Kurazumi, Y., Hirayama, K. and Kobayashi, Y. (1991) The Effective Radiation Area of the Human Body and Configuration Factors between the Human Body and Rectangular Planes and Measured by the Photographic Method, Part 2 Measurement for a Female and for the Surface Parts 
of a Male Body. Journal of Architecture, Planning and Environmental Engineering, 428, 67-75.

[93] Kurazumi, Y. and Tsuchikawa, T. (2004) Progress in Studies on Specific Data Related to Heat Balance Equation of the Human Body. Japanese Journal of Biometeorology, 41, 109-128.

[94] Underwood, W. (1966) The Solar Radiation Area of Man. Ergonomics, 9, 155-168. https://doi.org/10.1080/00140136608964361

[95] Fanger, P.O. (1970) Thermal Comfort. Danish Technical Press, Copenhagen.

[96] Miyamoto, S., Horikoshi, T. and Hirokawa, Y. (1998) Projected Area Factors of the Human Body at Standing Posture under Different Clothing Conditions. Journal of Architecture, Planning and Environmental Engineering, 513, 47-52.

https://doi.org/10.3130/aija.63.47_4 